\title{
CTRP Reference Gene Terminology
}

National Cancer Institute

\section{Source}

National Cancer Institute. CTRP Reference Gene Terminology. NCI Thesaurus. Code C142801.

A set of terms that is comprised of all the genes referenced in $\mathrm{NCl}$-sponsored clinical trials. 